\title{
Effectiveness of a home fortification programme with multiple micronutrients on infant and young child development: a cluster-randomised trial in rural Bihar, India
}

\author{
Leila M. Larson ${ }^{1}$, Melissa F. Young ${ }^{1,2}$, Patricia J. Bauer ${ }^{3}$, Rukshan Mehta ${ }^{1}$, Amy Webb Girard ${ }^{1,2}$, \\ Usha Ramakrishnan $^{1,2}$, Pankaj Verma ${ }^{4}$, Indrajit Chaudhuri ${ }^{4}$, Sridhar Srikantiah ${ }^{4}$ and Reynaldo Martorell ${ }^{1,2}$ \\ ${ }^{1}$ Nutrition and Health Sciences Program, Laney Graduate School, Emory University, Atlanta, GA 30322, USA \\ ${ }^{2}$ The Hubert Department of Global Health, Rollins School of Public Health, Emory University, Atlanta, GA 30322, USA \\ ${ }^{3}$ Department of Psychology, Emory University, Atlanta, GA 30322, USA \\ ${ }^{4}$ CARE India, 800013 Bihar, India
}

(Submitted 24 January 2018 - Final revision received 17 April 2018 - Accepted 19 April 2018)

\section{Abstract}

Research demonstrates the importance of nutrition for early brain development. Few studies have examined the effectiveness of multiple micronutrient powders (MNP) on child development. This study examined the impacts of home fortification with MNP on motor and mental development, executive function and memory of children living in Bihar. This two-arm cluster-randomised effectiveness trial selected seventy health sub-centres to receive either MNP and nutrition counselling (intervention) or nutrition counselling alone (control) for 12 months. Frontline health workers delivered the intervention to all households in study communities with a child aged 6-18 months. Data were collected using cross-sectional surveys at baseline and endline by selecting households from intervention (baseline, $n$ 2184; endline, $n$ 2170) and control (baseline, $n$ 2176; endline, $n$ 2122) communities using a two-stage cluster-randomised sampling strategy. Children in the intervention group had a significantly larger improvement from baseline to endline compared with those in the control group on scores for motor and mental development (Cohen's $d$, motor $=0 \cdot 12 ; 95 \%$ CI 0.03, 0.22; mental $=0 \cdot 15 ; 95 \%$ CI 0.06, 0.25). Greater impacts of MNP on motor and mental development were observed in children from households with higher stimulation scores at baseline compared with those with lower stimulation (Cohen's $d$, motor $=0.20 v .0 .09$; mental $=0.22 v \cdot 0 \cdot 14 ; P_{\text {interaction }}<0.05$ ). No significant treatment differences were seen for executive function or memory. Home fortification with MNP through the existing health infrastructure in Bihar was effective in improving motor and mental development and should be considered in combination with other child development interventions such as stimulation.

\section{Key words: Child development: Motor development: Mental development: Micronutrients: Multiple micronutrient powder}

Estimates indicate that 250 million children (43\%) under 5 years of age do not fulfil their developmental potential in low- and middle-income countries (LMIC) ${ }^{(1)}$. Poor development in early life has ongoing and long-term implications on school achievement and income and productivity (which tend to be lower), high fertility and poor care for the next generation ${ }^{(2,3)}$. Proper nutrition especially during the first $1000 \mathrm{~d}$ can influence early development directly through brain development, and indirectly through reducing illness and improving growth, as well as enhancing the child's interactions with their environment ${ }^{(4)}$.

Recent meta-analyses and reviews document the efficacy of early child nutrition interventions on development especially among children under 2 years of age from $\mathrm{LMIC}^{(5-7)}$. Home fortification with multiple micronutrient powders (MNP) is a simple intervention that requires caregivers to mix a sachet of micronutrients into their child's food before feeding. Although several studies have evaluated the efficacy of MNP on young child development, few have studied the effectiveness of such programmes when delivered using the existing government health infrastructure ${ }^{(8-10)}$. Evidence from effectiveness trials demonstrates the potential for such programmes to benefit at-risk populations with little additional investment and is important if state governments are to transition to scale at a regional level ${ }^{(8)}$.

Despite overall benefits of postnatal food and micronutrient interventions, trials have yielded inconsistent results on child development $^{(6)}$. One reason could be the outcome measurement. Global measures of child development, such as the Bayley's Scales of Infant and Child Development, which are typically used in nutrition studies in $\mathrm{LMIC}^{(6)}$, can capture effects on motor and mental development broadly. Because of

Abbreviations: ASHA, Accredited Social Health Activist; AWC, Anganwadi Centre; AWW, Anganwadi Worker; DMC-II, Developmental Milestones Checklist II; FCI, Family Care Indicators; FLW, front-line health worker; HSC, health sub-centre; MNP, multiple micronutrient powder; MUAC, mid-upper arm circumference.

* Corresponding author: L. M. Larson, email leilamlarson@gmail.com 
nutrients' specific functions in synaptic efficiency, myelination and hippocampal development ${ }^{(11)}$, micronutrient interventions may differentially affect specific cognitive functions that are masked in higher-order assessment tools. Two such specific processes that underlie early cognitive development ${ }^{(12-14)}$ and are hypothesised to be related to nutritional status are executive functions (cognitive processes associated with mental control and self-regulation $)^{(15,16)}$ and memory ${ }^{(17-19)}$.

The objectives of the current study were to examine the effectiveness of home fortification with MNP on motor and mental development of children aged 6-18 months, and on executive function and declarative memory of children aged 12-18 months. We hypothesised that children from communities receiving the intervention would score higher on development, executive function and memory tests than children from control communities. Our study was a cluster-randomised effectiveness trial conducted in rural India, a country that contributes a quarter of all children at risk of poor development worldwide ${ }^{(20)}$. The trial was designed based on a request from the government of Bihar for further evidence to address micronutrient deficiencies and their consequences in this population. Although MNP have previously been used in India $^{(21,22)}$, to our knowledge no large-scale effectiveness trials have examined the potential impact of such a programme using the existing front-line health workers (FLW) on early child development in this context.

\section{Methods}

This study was a collaboration between CARE India and Emory University. It was approved by the Institutional Review Boards of the 3rd Futures Group, Delhi, India, St John's Medical College
\& Hospital Institutional Ethics Committee, Bangalore, India, and Emory University, Atlanta, USA, and registered with the US National Institute of Health as a clinical trial (www. ClinicalTrials.gov; NCT02593136).

\section{Setting}

The government of Bihar, in partnership with the Bill and Melinda Gates Foundation and CARE India, launched the Integrated Family Health Initiative (IFHI) in 2011 to address pressing health challenges faced by its population. The IFHI identified childhood anaemia (at $64 \%$ in children under 5 years in Bihar) $)^{(23)}$ as one of the major public health priorities to be targeted. On the basis of evidence ${ }^{(24)}$, home fortification with MNP was identified as an innovative strategy to address this priority. The programme was delivered by government FLW with the support of CARE India, the primary implementing partner of IFHI and Emory University that provided nutrition technical support. The goal of the study was to determine the effectiveness of the programme in one district of Bihar before potential state-wide scale-up.

Extensive formative research was conducted between 2012 and 2014 to establish viability of the MNP product in this context (e.g. acceptability of the product, messaging and visual messaging) ${ }^{(25)}$. The current study was started following positive evidence for its acceptability by the community.

\section{Study design and participants}

We conducted a 12-month two-arm cluster-randomised effectiveness trial in West Champaran district of Bihar, India, between January 2015 and December 2015 (Fig. 1). In India,

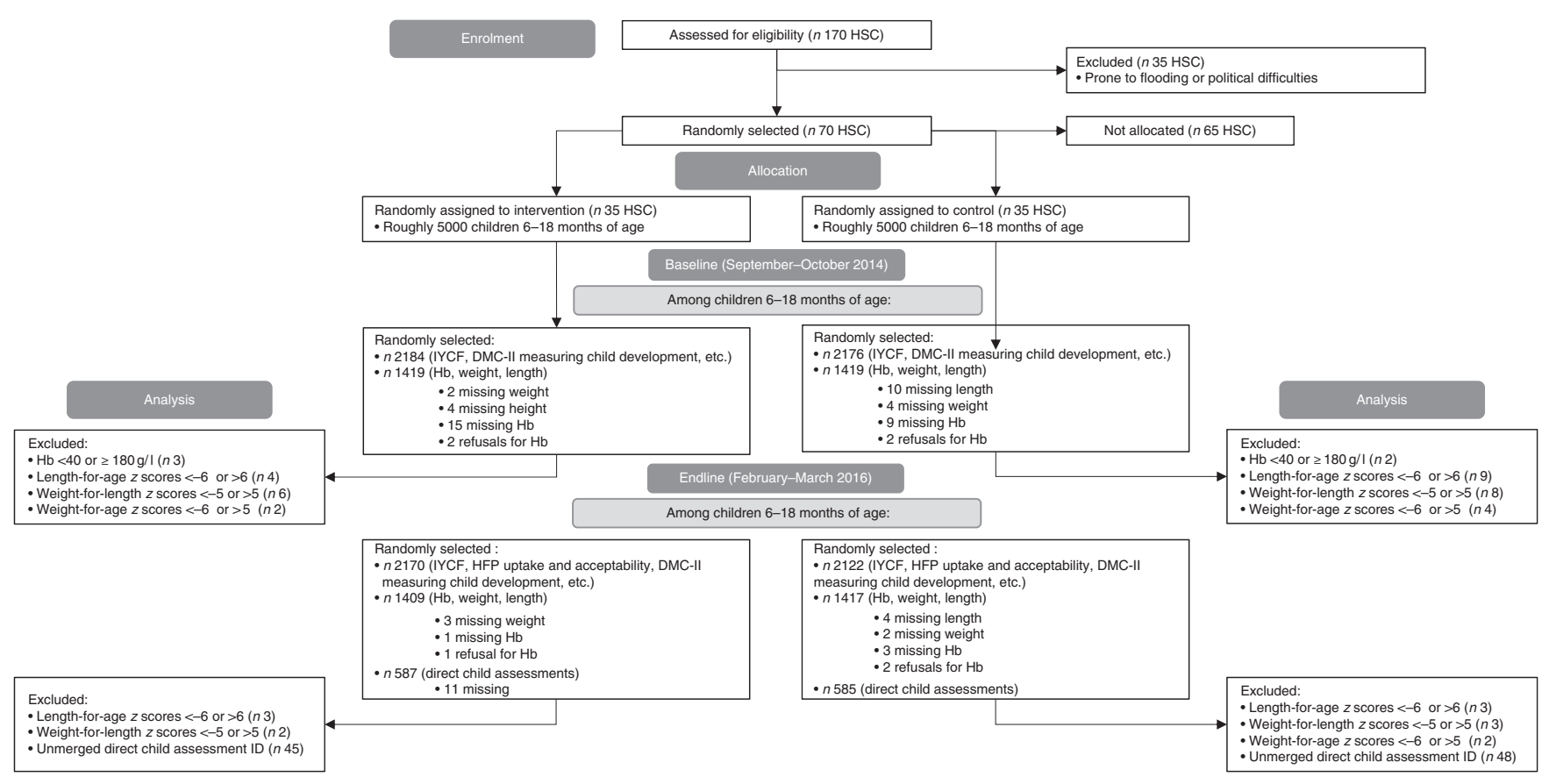

Fig. 1. CONSORT flow diagram. Owing to families being out-of-home during the harvest and festival season, which coincided with our endline, forty-eight households were under-sampled for the household survey (total 4292 at endline). At baseline and endline, $1 \%$ of children were oversampled for anthropometry (total 2838 at baseline; 2826 at endline). At endline, eleven households were missing direct child assessments owing to sickness (total 1172). DMC-II, Developmental Milestones Checklist II; IYCF, infant and young child feeding; HSC, health sub-centre; HFP, home fortification project. 
districts are subdivided into blocks (subdistricts). Four blocks were purposefully chosen to include two blocks close to and two blocks far from district headquarters. Within each of these four blocks, health sub-centres (HSC) that were prone to flooding and political difficulties ( $n$ 35) were excluded. Out of 135 HSC communities, seventy were randomly assigned, using a simple randomisation method with random number generator, to intervention or control communities (Fig. 1); all families with children aged 6-18 months in these communities received complementary feeding counselling, and intervention families additionally received the home fortification product, a MNP labelled Jeevan Jyoti (the name means 'the light of life' in Hindi, chosen by community members as part of formative research).

We utilised a nested cross-sectional pre-test-post-test control group design ${ }^{(26)}$ whereby two cross-sectional surveys of children aged 6-18 months were used to assess the change in outcomes. This design is appropriate for evaluations of universal programmes. The baseline ( $n$ 4360) and endline ( $n$ 4292) surveys were conducted from August to September 2014 and from February to March 2016, respectively. Inclusion criteria for survey enrolment were child's age above 6 months and below 18 months, half of whom were 6-11.9 months of age and the other half were 12-18 months of age. Cross-sectional surveys of children aged 6-18 months at baseline and endline were chosen in order to stay as true to an effectiveness study as possible and to examine children who were consuming complementary foods and therefore would have the potential to benefit from MNP.

For the baseline and endline evaluation, a household listing (list of eligible households) was performed before starting the survey. In HSC with five or more Anganwadi centres (AWC), simple random sampling (SRS) was used to select five AWC for which household listing was performed. Using the household listings, thirty-one children aged 6-11.9 months and thirty-one children aged 12-17.9 months from each HSC were chosen using SRS to be included in the household survey, which included questions on their child's mental and motor development. Refusals for the household survey were replaced ( $n 2$ at baseline). From each age group in each HSC, twenty of the thirty-one children were randomly selected to be measured for anthropometry. At endline only, seventeen children in each HSC from the older age group who received the household survey and anthropometry were chosen using SRS to be tested using direct child assessments, through game-like interactions with each child (refer to the 'Measurements' section). Because additional funding was obtained after the baseline was completed, direct child assessments were performed only at endline (Fig. 1).

During the survey, supervisors conducted $10 \%$ back-checks that involved re-interviewing the caregiver on a random subset of questions and comparing results with the field investigators' results, and $10 \%$ spot-checks that involved observing interviews.

\section{Intervention}

The counselling and Jeevan Jyoti MNP were delivered to households with a child aged 6-18 months at no cost to the families, by the local community FLW, the Accredited Social
Health Activists (ASHA) and the Anganwadi Workers (AWW). ASHA and AWW coordinated so that they each visited approximately half the households in their catchment area. ASHA are local women trained as health educators under the Ministry of Health. AWW are part of the Integrated Child Development Services programme in India; in addition to family planning and nutrition counselling and supplementation, they administer preschool activities for children aged 3-5 years. Each HSC is home to approximately seven ASHA and seven AWW. Typically, a pair of one AWW and one ASHA work within one AWC catchment area. The project area included a total of roughly 10000 children.

FLW were advised to provide all households (intervention and control communities) with counselling and information pamphlets on infant and young child feeding (IYCF) practices that included guidance on breast-feeding, food variety, frequency of feeding, food consistency, food quantity, hand washing and hygiene practices.

In intervention communities, FLW distributed a box of 30 MNP sachets to the caregivers of children aged 6-18 months on a monthly basis and provided instructions to mix one MNP sachet into the child's food every day. Each MNP sachet contained $12.5 \mathrm{mg}$ of Fe as ferrous fumarate, $5 \mathrm{mg}$ of zinc gluconate, $0.16 \mathrm{mg}$ of folic acid, $0.3 \mathrm{mg}$ of vitamin A acetate, $30 \mathrm{mg}$ of ascorbic acid, $0.9 \mu \mathrm{g}$ of vitamin $\mathrm{B}_{12}$ and $90 \mu \mathrm{g}$ of iodine (roughly one Recommended Dietary Allowance ${ }^{(27)}$ for most nutrients). Children aged in and out of the programme during its 1-year duration. FLW were advised to provide four boxes of MNP to children during each of the time periods of 6-12 and 12-18 months in accordance with World Health Organization recommendations ${ }^{(24)}$. In intervention communities, the IYCF pamphlet also included detailed graphic instructions on the use of MNP. At the start of the programme, and on a monthly basis over the project period, meetings and refresher trainings were held at the HSC level between CARE project staff and FLW to go over the programme, the proper use of MNP sachets and their distribution, the IYCF counselling and collection of monthly monitoring data.

\section{Blinding and training}

Both data collection and data entry were blinded to the intervention. Data collectors were present in the communities only before and after the intervention.

The data collection team comprised supervisors, household survey data collectors, anthropometry/ $\mathrm{Hb}$ data collectors and research assistants for the direct child assessments. All had received minimal information on the nutrition programme and were unaware of the households' status. All had at least completed secondary school. Local research assistants conducting direct child assessments were bachelors, masters or $\mathrm{PhD}$ students in Psychology or Social Science. All data collectors and research assistants were trained in their respective work over a 2 -week period. The questionnaire and direct child assessment tasks were pilot tested on children from Bihar and adapted before starting the survey. Training on direct child assessments was performed by L. M. L. and a local psychologist. Ongoing monitoring ensured adherence to study protocols. 


\section{Ethical considerations}

Written informed consent (or thumb print from participants unable to write their name) was obtained from all caregivers participating in the survey. Participants were informed that the decision to participate was entirely theirs and that, if they chose to participate, they could withdraw at any time. Refusal to participate in the survey did not exclude them from receiving the MNP or other services from the FLW they would normally receive. Consent for child anthropometry, $\mathrm{Hb}$ and direct child development assessments was obtained separately, as these data were obtained in a subset of the children; caregivers could opt out of having these measurements, and still be included in the general components of the survey.

\section{Measurements}

All questionnaires and tasks were administered in Hindi or Bhojpuri, the local dialect, based on the fluency of the respondent. The questionnaire was translated and backtranslated to ensure that the language was correct. Data collectors read all questions out loud to mothers or caregivers.

\section{Developmental milestones. Primary outcomes were motor} (gross and fine) and mental (language and personal-social) development, assessed at baseline and endline using the Developmental Milestones Checklist II (DMC-II), a seventy-fiveitem parent report ${ }^{(28)}$. A subset of the DMC along with seven cognitive items showed convergent validity against the Bayley Scales of Infant and Toddler Development ${ }^{(29)}$. Motor development includes the sum of scores from the gross and fine motor subscales; mental development includes the sum of scores from the language, personal-social and cognitive subscales. Items were scored as 1 if the child had performed this activity and 0 if the child had not yet performed it. This measure has been validated in India, Burkina Faso, Kenya and Ghana ${ }^{(28,30-32)}$.

Executive function. Executive function was a secondary outcome measured at endline only in children aged 12-18 months using a direct child assessment. Executive function and memory (as described below) were measured in children aged 12-18 months only because we wanted to examine these specific functions in children who would have had the opportunity to consume the MNP for a longer period of time. Research assistants worked in pairs; one interacted with the child, whereas the other took notes and scored the measure. In the A-not-B task ${ }^{(33)}$, the child is shown a desirable object hidden under a cloth (location A), within the child's reach. After a brief delay, the child is allowed to search for and find the object. After several successes finding the object at a particular location, the object is then hidden under a cloth at an alternate location (B). Here, correct performance depends on the child's ability to update their memory of the hiding place, as well as to inhibit the response of searching at the location where the object was previously found. Each child was given four trial attempts to retrieve the object successfully under a given delay. If the child was successful in retrieving the object on two consecutive trials, the side of hiding was changed and the delay incremented by $3 \mathrm{~s}$. This was continued until the child failed to retrieve the object on two consecutive trials or the maximum of 12-s delay was successfully passed (delays: 0, 3, 6, 9 and 12s) (online Supplementary Fig. S1). Further details on the test are described in the online Supplementary Table S1.

Memory test. Memory was another secondary outcome measured at endline only in children aged 12-18 months. In the Elicited Imitation task ${ }^{(34,35)}$, which measures episodic memory, the child was tested for immediate and delayed recall of two 2-step tasks and two 3-step sequences of action. The research assistant, sitting in front of the child, modelled and narrated the sequence of actions in succession two times. They then returned the props to the child and invited them to imitate the exact sequence. Each child was tested on one 2-sequence task and one 3 -sequence task immediately after modelling and one 2-sequence task and one 3-sequence task after a delay of $10 \mathrm{~min}$ (different tasks to those used for immediate recall). A 10-min delay is long enough to reveal a deficit in individuals with compromised memory function owing to medial-temporal lobe damage ${ }^{(36)}$, and thus it is especially sensitive to the developmental integrity of the hippocampus ${ }^{(34)}$. To score the children's behaviour, for each sequence, we calculated a total number of individual target actions produced (maximum $=2$ for 2 -sequence tasks, maximum $=3$ for 3 -sequence tasks) and the total number of pairs of actions produced in the target order (maximum $=1$ for 2-sequence tasks, maximum $=2$ for 3-sequence tasks). Only the first occurrence of each target action was considered so as to reduce credit that might be received owing to chance or trial and error ${ }^{(34)}$. Further details on the test are described in the online Supplementary Table S1.

Stimulation, diet and morbidity. The Family Care Indicators (FCI), a nine-item parent-report measure, previously validated in South $\mathrm{Asia}^{(37)}$, was used to assess stimulating caregiving. The FCI includes questions on play materials, spending time outside the home with the child and reading, telling stories, singing, playing and naming and counting with the child. A Wealth Index, using five categories, was calculated using Principal Component Analysis with family assets, type of household, land ownership and source of drinking water; this was done separately for baseline and endline data. A child dietary diversity score, minimum meal frequency value and minimum acceptable diet value were created according to World Health Organization guidelines ${ }^{(38)}$. Food deprivation was assessed through mothers' report using the cross-culturally validated Household Hunger Scale ${ }^{(39)}$. Households were classified as food deprived or not based on their responses to the four-item Likert scale. Recent morbidity was measured as any fever, cough or diarrhoea in the past 2 weeks reported by the caregiver. A total of thirty-two field investigators, trained and standardised, collected the household survey information, including the DMC-II, at baseline and endline.

Anthropometry and $\mathrm{Hb}$. Anthropometric measurements including weight, length and mid-upper arm circumference (MUAC) were taken at baseline and endline following standard 
procedures $^{(40)}$. Weight was assessed with the Seca 874 (Seca) and length with the Seca 417. Length-for-age, weight-for-length and weight-for-age $z$ scores were calculated using the WHO 2006 child growth standards ${ }^{(40)} ; z$ scores $<-2$ were used to define stunting, wasting and underweight, respectively; $z$ scores $<-3$ were used to define severe stunting, severe wasting and severe underweight. MUAC tapes (S0145620 MUAC, Child 11.5 Red/PAC-50) were used to measure MUAC. $\mathrm{Hb}$ was measured with the HemoCue $\mathrm{Hb}$ 201+ Analyzar (HemoCue). Blood samples were taken using a heel prick from children aged $6-11$ months, and a finger prick for children aged 12-18 months. Child anaemia was defined as mild if $100 \mathrm{~g} / \mathrm{l} \leq \mathrm{Hb}<110 \mathrm{~g} / \mathrm{l}$, moderate if $70 \mathrm{~g} / \mathrm{l} \leq \mathrm{Hb}<100 \mathrm{~g} / \mathrm{l}$ and severe if $\mathrm{Hb}<70 \mathrm{~g} / \mathrm{l}^{(41)}$. If children were found to be severely anaemic, they were referred to the nearest primary health centre. Effects on anaemia and stunting have been reported elsewhere ${ }^{(42)}$.

\section{Sample size estimation}

For the primary outcome of mental and motor development using the DMC-II, a sample size of 2170 children per group across seventy clusters was calculated to detect an effect size of 0.1 or larger, $80 \%$ power, $\alpha$ of 0.05 and an intra-cluster correlation coefficient of $0 \cdot 01$. For the secondary outcomes of executive function and memory, a sample size of 546 per group across seventy clusters was calculated to detect an effect size of 0.25 or larger, assuming a power of $0 \cdot 8$, an $\alpha$ of $0 \cdot 05$, an intra-cluster correlation coefficient of 0.2 and a refusal rate of $5 \%$. These estimates were based on the literature on executive function and memory, and related child development interventions ${ }^{(43-46)}$.

\section{Statistical analyses}

Data were analysed using SAS 9.4 (SAS Institute). Children with $\mathrm{Hb}$ measurements below $40 \mathrm{~g} / \mathrm{l}$ or above or equal to $180 \mathrm{~g} / \mathrm{l}^{(47)}$ $(0.2 \%$ at baseline, $0.01 \%$ at endline), or children with lengthfor-age $z$ scores $<-6$ or $>6(0.2 \%$ at baseline, $0.2 \%$ at endline), weight-for-length $z$ scores $<-5$ or $>5$ ( $0.6 \%$ at baseline, $0.02 \%$ at endline) or weight-for-age $z$ scores $<-6$ or $>5$ ( $0.5 \%$ at baseline, $0.01 \%$ at endline) were omitted from the analysis (Fig. 1) ${ }^{(48)}$.

The effect of the intervention on change in DMC-II scores (mental and motor development, and all subscales separately) was identified by linear mixed effects models with a fixed effect of intervention group and a random effect of HSC cluster with nested AWC. We used a difference-in-difference approach to run intent-to-treat analyses (model 1) using intervention group, survey (baseline $v$. endline), their interaction and age of the child in months as the only fixed effects. Model 2 used the same fixed effects as Model 1, in addition to covariates that were significantly different between the intervention and control communities at baseline (baseline $\mathrm{Hb}$ and baseline household stimulation score, wealth index, maternal education, caste and young mother status). This study used two cross-sectional surveys, and did not follow-up the same children; therefore, in order to impute a baseline $\mathrm{Hb}$ and baseline household stimulation score to endline children, we used the mean of the $\mathrm{Hb}$ concentration and household stimulation score for children in their same cluster, stratified by sex and age group. The interaction was tested by using the standard error and denominator df that reflected the HSC level with nested AWC. Cohen's $d$ effect sizes are reported for each outcome.

Effects of the intervention on executive function and memory outcomes were examined using linear and generalised linear mixed models with a fixed effect of intervention group and random effect of HSC cluster with nested AWC. Outcomes of interest on the A-not-B task were: (1) ability to tolerate either 3, 6,9 or $12 \mathrm{~s}$, or not tolerating any delay; (2) the ability to find the object under cloth A; and (3) the ability to find the object under cloth B. Outcomes from the Elicited Imitation tasks included: (1) number of actions completed in all sequences (continuous) and (2) number of pairs of actions completed in the correct order in all sequences (continuous). All sequences were summed because there was no significant difference in the outcomes for sequences performed with or without the 10-min delay. Performance on the tasks during the time recorded as 'baseline' (pre-demonstration) was significantly different from that recorded post demonstration, indicating that the actions performed post demonstration were due, as intended, to memory. Model 1 was intent to treat adjusting for age of the child in months, and model 2 adjusted for the same covariates as those described for model 2 with the DMC-II scores, in addition to child baseline mental development scores using the DMC-II, as well as the research assistant testing the child. Concurrent validity of the A-not-B and Elicited Imitation tasks was examined by the associations between outcomes for each test and age of the child. Cohen's $d$ effect sizes were calculated by taking a difference of the change in scores between groups (or difference in scores between groups for measurements only conducted at endline) divided by a pooled standard deviation.

Using model 2, we examined effect modification on mental and motor development scores using the DMC-II and the outcomes of the A-not-B and Elicited Imitation tasks, from level of baseline household FCI stimulation (dichotomised as low $v$. high based on a score below/equal to or above the median score of 5) and continuous baseline Hb concentrations. We also examined dose-response within the intervention group using number of MNP sachets consumed by the child in the past month (dichotomised as $<10 v$. $\geq 10$ sachets in children from intervention communities at endline only). Baseline household FCI stimulation scores and baseline $\mathrm{Hb}$ concentrations were imputed for endline children by taking a mean of the FCI score or $\mathrm{Hb}$ concentration within baseline children from the same HSC of the same sex and age group. There was little (7\%) overlap between children with high baseline stimulation scores and children having consumed $\geq 10$ MNP sachets over the past month, indicating that the two measures are examining different outcomes. Statistical significance was defined as $P$ value $<0 \cdot 05$.

\section{Quality control}

Reliability of the data collectors' scores was established by examining the relation between the field investigators' scores and those of an expert when assessing the same child, using five children, both at baseline and endline ${ }^{(40)}$. Reliability measurements for weight, height and MUAC yielded a Pearson's correlation coefficient between measurements of the investigators and expert of $>0.92$ and a coefficient of reliability 
(which measures the proportion of inter-subject variance due to measurement error) of $>0 \cdot 80$. Reliability of the research assistants on direct child assessments was difficult to establish given the tasks tested executive function and memory; any re-test would have yielded biased responses from the child. Therefore, all research assistants practiced the tasks on children for $3 \mathrm{~d}$ while being observed by the trainers. Only those who performed the assessments correctly, as determined by the first author and a local psychologist, were retained. A field coordinator and supervisor monitored assessments throughout data collection to ensure fidelity to the protocols.

Intra-cluster correlation coefficients for each outcome were calculated using the between- and within-cluster variability: $<0.01$ for motor, 0.02 for mental, $<0.01$ for gross motor, 0.03 for fine motor, 0.02 for language, 0.03 for personal-social, 0.05 for cognitive scores, $0 \cdot 10$ for memory scores and 0.07 for executive function scores.

\section{Results}

\section{Baseline characteristics of children}

At baseline, $60 \%$ of mothers had no schooling, mean maternal age was 25.2 years, mean parity was 2.7 children, $72 \%$ of children were anaemic, 33\% were stunted, $27 \%$ were wasted and $42 \%$ were underweight. At baseline, the mean motor and mental development score among all children was 17.8 out of 32 (95\% CI $17 \cdot 6,18 \cdot 0)$ and $24 \cdot 9$ out of 50 (95\% CI $24 \cdot 4,25 \cdot 3)$, respectively. The intervention and control groups matched on most key demographic and child nutritional characteristics at baseline (Tables 1 and 2). However, the intervention group had significantly higher prevalence of any maternal education, higher mean FCI score, lower mean $\mathrm{Hb}$ concentration and higher mean score on the cognitive subscale of the DMC-II. Among children living in intervention communities at endline, $40 \%$ received ten or more MNP sachets over the month before the survey.

\section{Concurrent validity of child development measures}

Validity of the DMC-II in this context is reported elsewhere ${ }^{(31)}$. In a bivariate regression, outcomes on the A-not-B and Elicited Imitation tasks are significantly $(P<0.001)$ associated with child age. Each month of age between 12 and 18 months was associated with a $13 \%$ (OR 1.13; $95 \%$ CI 1.06, 1.20) higher odds of tolerating three more seconds of delay before finding a hidden object in the A-not-B task, a 0.28 (95\% CI 0.22, 0.34) increase in the number of actions complete in the correct order across all Elicited Imitation sequences and a $0 \cdot 19$ (95\% CI $0 \cdot 15,0,24)$ increase in the number of pairs of actions complete in the correct order. For the Elicited Imitation tasks, children's baseline performance (scores for actions completed before research assistant demonstrating the sequences) was significantly different from their post-demonstration performance for each sequence, meaning that performance was owing to memory and not spontaneous production of actions or sequences of

Table 1. Household characteristics at baseline and endline for the multiple micronutrient powders (MNP) intervention group and the control group*

(Percentages and numbers; mean values and standard deviations)

\begin{tabular}{|c|c|c|c|c|c|c|c|c|}
\hline & \multicolumn{4}{|c|}{ Baseline } & \multicolumn{4}{|c|}{ Endline } \\
\hline & \multicolumn{2}{|c|}{$\begin{array}{l}\text { Intervention group } \\
\qquad(n 2184)\end{array}$} & \multicolumn{2}{|c|}{$\begin{array}{l}\text { Control group } \\
\quad(n 2176)\end{array}$} & \multicolumn{2}{|c|}{$\begin{array}{l}\text { Intervention group } \\
\qquad(n 2170)\end{array}$} & \multicolumn{2}{|c|}{$\begin{array}{l}\text { Control group } \\
\quad(n 2122)\end{array}$} \\
\hline & $\%$ & $n$ & $\%$ & $n$ & $\%$ & $n$ & $\%$ & $n$ \\
\hline \multicolumn{9}{|l|}{ Religion } \\
\hline Hindu & 78.1 & 1701 & 79.5 & 1730 & $75 \cdot 7$ & 1646 & 78 & 1655 \\
\hline Muslim & 21.9 & 478 & 20.5 & 445 & $24 \cdot 3$ & 529 & 22 & 466 \\
\hline \multicolumn{9}{|l|}{ Maternal age (years) } \\
\hline Mean & \multicolumn{2}{|c|}{$25 \cdot 2$} & \multicolumn{2}{|c|}{$25 \cdot 2$} & \multicolumn{2}{|c|}{$25 \cdot 0$} & \multicolumn{2}{|c|}{$25 \cdot 2$} \\
\hline $\mathrm{SD}$ & \multicolumn{2}{|c|}{4.7} & \multicolumn{2}{|c|}{4.8} & \multicolumn{2}{|c|}{4.7} & \multicolumn{2}{|c|}{4.7} \\
\hline \multicolumn{9}{|l|}{ Paternal age (years) } \\
\hline Mean & \multicolumn{2}{|c|}{29.5} & \multicolumn{2}{|c|}{$29 \cdot 4$} & \multicolumn{2}{|c|}{28.9} & \multicolumn{2}{|c|}{$29 \cdot 3$} \\
\hline SD & \multicolumn{2}{|c|}{$5 \cdot 7$} & \multicolumn{2}{|c|}{5.9} & \multicolumn{2}{|c|}{$5 \cdot 3$} & \multicolumn{2}{|c|}{5.5} \\
\hline Maternal education & & & & & & & & \\
\hline Any schooling & $42 \cdot 1$ & 918 & 37.7 & 819 & $48 \cdot 0$ & 1043 & 44.9 & 952 \\
\hline \multicolumn{9}{|l|}{ Paternal education } \\
\hline Any schooling & $65 \cdot 1$ & 1417 & $62 \cdot 8$ & 1360 & 68.2 & 1453 & 67.4 & 1397 \\
\hline \multicolumn{9}{|l|}{ Caste (self-reported) } \\
\hline Scheduled caste & $24 \cdot 1$ & 524 & $26 \cdot 4$ & 572 & $18 \cdot 1$ & 394 & 21 & 446 \\
\hline Scheduled tribe & $7 \cdot 3$ & 159 & $9 \cdot 3$ & 201 & $7 \cdot 2$ & 156 & 11.3 & 241 \\
\hline Other backwards caste & $17 \cdot 0$ & 370 & 15 & 325 & 13.7 & 298 & 11 & 234 \\
\hline \multicolumn{9}{|l|}{ Parity } \\
\hline Mean & \multicolumn{2}{|c|}{$2 \cdot 7$} & \multicolumn{2}{|c|}{$2 \cdot 7$} & \multicolumn{2}{|c|}{$2 \cdot 6$} & \multicolumn{2}{|c|}{$2 \cdot 7$} \\
\hline SD & & & & & & & & \\
\hline Family Care Indicators sc & & & & & & & & \\
\hline Mean & & & & & & & & \\
\hline SD & & & & & & & & \\
\hline
\end{tabular}

* At baseline, total $n 4360$ for all measurements. At endline, total $n 4292$ for all measurements. The self-reported castes are officially designated groups in India. 
Table 2. Demographic and clinical characteristics of children at baseline and endline for the multiple micronutrient powders (MNP) intervention group and the control group*

(Percentages and numbers; mean values and standard deviations)

\begin{tabular}{|c|c|c|c|c|c|c|c|c|}
\hline & \multicolumn{4}{|c|}{ Baseline } & \multicolumn{4}{|c|}{ Endline } \\
\hline & \multicolumn{2}{|c|}{$\begin{array}{l}\text { Intervention group } \\
(n 2184)\end{array}$} & \multicolumn{2}{|c|}{$\begin{array}{c}\text { Control group } \\
(n 2176) \\
\end{array}$} & \multicolumn{2}{|c|}{$\begin{array}{l}\text { Intervention group } \\
(n 2170)\end{array}$} & \multicolumn{2}{|c|}{$\begin{array}{l}\text { Control group } \\
\quad(n \text { 2122) }\end{array}$} \\
\hline & $\%$ & $n$ & $\%$ & $n$ & $\%$ & $n$ & $\%$ & $n$ \\
\hline \multicolumn{9}{|l|}{ Age (months) } \\
\hline $6-11$ & $50 \cdot 2$ & 1096 & $51 \cdot 1$ & 1111 & $46 \cdot 9$ & 1021 & $46 \cdot 3$ & 983 \\
\hline $12-18$ & 49.8 & 1087 & 48.9 & 1065 & $53 \cdot 1$ & 1154 & 53.7 & 1141 \\
\hline \multicolumn{9}{|c|}{ Age in months in the $6-11$-month age group } \\
\hline Mean & \multicolumn{2}{|c|}{$8 \cdot 6$} & \multicolumn{2}{|c|}{$8 \cdot 7$} & \multicolumn{2}{|c|}{8.4} & \multicolumn{2}{|c|}{$8 \cdot 4$} \\
\hline SD & \multirow{2}{*}{\multicolumn{2}{|c|}{$1 \cdot 7$}} & \multirow{2}{*}{\multicolumn{2}{|c|}{$1 \cdot 7$}} & \multicolumn{2}{|c|}{1.7} & \multicolumn{2}{|c|}{1.7} \\
\hline \multicolumn{7}{|c|}{ Age in months in the $12-18$-month age group } & & \\
\hline Mean & \multirow{2}{*}{\multicolumn{2}{|c|}{$14 \cdot 1$}} & \multicolumn{2}{|c|}{$13 \cdot 9$} & \multicolumn{2}{|c|}{$14 \cdot 6$} & \multicolumn{2}{|c|}{$14 \cdot 6$} \\
\hline SD & & & & & & & & \\
\hline Sex & \multicolumn{2}{|c|}{$1 \cdot 8$} & & & & & & \\
\hline Girls & 48.7 & 1062 & $50 \cdot 8$ & 1103 & $47 \cdot 2$ & 1026 & $46 \cdot 6$ & 990 \\
\hline Dietary diversity score (out of 7 ) & & & & & & & & \\
\hline Mean & & & & & & & & \\
\hline SD & & & & & & & & \\
\hline Minimum meal frequency achieved & 64.5 & 1380 & $67 \cdot 1$ & 1428 & $71 \cdot 8$ & 1418 & $75 \cdot 1$ & 1451 \\
\hline Minimum acceptable diet achieved & 14.4 & 314 & 16 & 348 & $22 \cdot 3$ & 486 & 23.1 & 491 \\
\hline Any household hunger & 9.7 & 209 & $9 \cdot 3$ & 201 & 4.3 & 93 & 4.6 & 97 \\
\hline Any recent child morbidity & $75 \cdot 2$ & 1642 & $76 \cdot 2$ & 1658 & $51 \cdot 7$ & 1125 & $54 \cdot 4$ & 1157 \\
\hline Fever & $64 \cdot 8$ & 1415 & 67 & 1459 & 34.7 & 755 & $37 \cdot 6$ & 799 \\
\hline Cough & $54 \cdot 3$ & 1184 & 55.5 & 1205 & 39.5 & 859 & 39.4 & 837 \\
\hline Diarrhoea & 11.6 & 253 & $12 \cdot 1$ & 263 & $11 \cdot 1$ & 241 & $15 \cdot 6$ & 331 \\
\hline Anthropometry & & & & & & & & \\
\hline Length-for-age $z$ score & & & & & & & & \\
\hline Mean & & & & & & & & \\
\hline SD & & & & & & & & \\
\hline Weight-for-length $z$ score & & & & & & & & \\
\hline Mean & & & & & & & & \\
\hline SD & & & & & & & & \\
\hline Weight-for-age $z$ score & & & & & & & & \\
\hline Mean & & & & & & & & \\
\hline SD & & & & & & & & \\
\hline Mid-upper arm circumference & & & & & & & & \\
\hline Mean & & & & & & & & \\
\hline SD & & & & & & & & \\
\hline Anaemia & & & & & & & & \\
\hline Any $(\mathrm{Hb}<110 \mathrm{~g} / \mathrm{l})$ & $75 \cdot 3$ & 1062 & $69 \cdot 2$ & 977 & 64.4 & 910 & $66 \cdot 1$ & 934 \\
\hline Mild $(100 \mathrm{~g} / \mathrm{l} \leq \mathrm{Hb}<110 \mathrm{~g} / \mathrm{l})$ & $27 \cdot 5$ & 388 & 28.4 & 401 & $30 \cdot 8$ & 435 & 32 & 453 \\
\hline Moderate $(70 \mathrm{~g} / \mathrm{l} \leq \mathrm{Hb}<100 \mathrm{~g} / \mathrm{l})$ & $44 \cdot 8$ & 632 & 38.5 & 543 & $32 \cdot 4$ & 458 & 33.5 & 473 \\
\hline Severe $(\mathrm{Hb}<70 \mathrm{~g} / \mathrm{l})$ & 3.0 & 42 & $2 \cdot 3$ & 33 & 1.2 & 17 & 0.6 & 8 \\
\hline $\mathrm{Hb}(\mathrm{g} / \mathrm{l})$ & & & & & & & & \\
\hline Mean & & & & & & & & \\
\hline SD & & & & & & & & \\
\hline
\end{tabular}

action. These patterns are consistent with those in the wider literature using Elicited Imitation tasks ${ }^{(34)}$.

\section{Impact of multiple micronutrient powder intervention on motor and mental development}

DMC-II scores for mental and motor development and for each subscale, as well as Elicited Imitation task outcomes, were normally distributed. The difference-in-difference analyses for DMC-II scores indicated that scores of children from intervention communities increased significantly more than those of control communities in gross motor, language and personalsocial development subscales $(P<0 \cdot 01)$ (Table 3$)$. As a whole, the change in motor and mental development of children between the two time points was larger for the intervention group children than the control group children (Cohen's $d$ effect size for motor $=0.12(95 \%$ CI $0.03,0.22)$; for mental $=$ 0.15 (95\% CI $0.06,0.25)$ ) (online Supplementary Fig. S2 and S3). Examination by age showed that the change in scores for gross motor development was significantly larger in the intervention group than in the control group for children aged 6-11 months, whereas the change in language development 
Table 3. Developmental Milestones Checklist II (DMC-II) scores for children aged 6-18 months at baseline and endline for the multiple micronutrient powders (MNP) intervention group and the control group*

(Mean values and standard deviations; adjusted means and $95 \%$ confidence intervals)

\begin{tabular}{|c|c|c|c|c|c|c|c|c|c|c|c|c|c|c|}
\hline & \multicolumn{4}{|c|}{ Baseline } & \multicolumn{4}{|c|}{ Endline } & \multirow{2}{*}{\multicolumn{3}{|c|}{ Model 1}} & \multirow{2}{*}{\multicolumn{3}{|c|}{ Model 2}} \\
\hline & \multicolumn{2}{|c|}{$\begin{array}{l}\text { Intervention } \\
\text { (n 2183) }\end{array}$} & \multicolumn{2}{|c|}{$\begin{array}{l}\text { Control } \\
(n 2176)\end{array}$} & \multicolumn{2}{|c|}{$\begin{array}{l}\text { Intervention } \\
(n 2170)\end{array}$} & \multicolumn{2}{|c|}{$\begin{array}{l}\text { Control } \\
(n 2122)\end{array}$} & & & & & & \\
\hline & Mean & SD & Mean & SD & Mean & SD & Mean & $\mathrm{SD}$ & Effect size (mean) & $95 \% \mathrm{Cl}$ & $P$ & Effect size (mean) & $95 \% \mathrm{Cl}$ & $P$ \\
\hline \multicolumn{15}{|l|}{ All children } \\
\hline Motor development & $17 \cdot 8$ & $5 \cdot 4$ & $17 \cdot 9$ & $5 \cdot 3$ & $18 \cdot 8$ & $6 \cdot 6$ & 18.5 & $6 \cdot 4$ & 0.13 & $0.05,0.21$ & 0.003 & 0.12 & $0.03,0.22$ & 0.012 \\
\hline Mental development & 24.9 & $6 \cdot 8$ & $24 \cdot 8$ & $6 \cdot 8$ & $26 \cdot 2$ & 7.5 & $25 \cdot 4$ & 7.5 & $0 \cdot 16$ & $0.07,0.24$ & $<0.001$ & $0 \cdot 15$ & $0.06,0.25$ & 0.002 \\
\hline Gross motor & $11 \cdot 1$ & 4.0 & $11 \cdot 1$ & $4 \cdot 0$ & $12 \cdot 1$ & 4.9 & 11.9 & $4 \cdot 7$ & $0 \cdot 15$ & $0.07,0.23$ & 0.001 & $0 \cdot 15$ & $0.06,0.25$ & 0.002 \\
\hline Fine motor & $6 \cdot 7$ & 1.9 & 6.7 & 1.9 & $6 \cdot 6$ & $2 \cdot 1$ & $6 \cdot 6$ & $2 \cdot 0$ & 0.04 & $-0.04,0.13$ & 0.314 & 0.02 & $-0.08,0.12$ & 0.685 \\
\hline Language & 4.6 & 2.5 & 4.6 & 2.5 & $5 \cdot 4$ & $2 \cdot 7$ & $5 \cdot 1$ & $2 \cdot 6$ & $0 \cdot 16$ & $0.07,0.24$ & $<0.001$ & 0.17 & $0.07,0.26$ & 0.001 \\
\hline Personal-social & $16 \cdot 1$ & $3 \cdot 7$ & $16 \cdot 2$ & $3 \cdot 7$ & $16 \cdot 5$ & $4 \cdot 1$ & $16 \cdot 2$ & $4 \cdot 0$ & 0.14 & $0.06,0.23$ & 0.001 & 0.13 & $0.04,0.23$ & 0.006 \\
\hline Cognitive & $4 \cdot 2$ & 1.6 & $4 \cdot 1$ & 1.6 & $4 \cdot 3$ & $1 \cdot 7$ & $4 \cdot 1$ & $1 \cdot 7$ & 0.07 & $-0.02,0.15$ & 0.130 & 0.05 & $-0.04,0.15$ & 0.293 \\
\hline \multicolumn{15}{|c|}{ Children aged $6-11$ months } \\
\hline Motor development & 14.5 & 4.0 & $15 \cdot 0$ & $4 \cdot 2$ & $13 \cdot 7$ & $4 \cdot 7$ & $13 \cdot 6$ & 4.6 & 0.14 & $0.02,0.26$ & 0.023 & $0 \cdot 16$ & $0.02,0.29$ & 0.024 \\
\hline Mental development & $21 \cdot 6$ & $5 \cdot 8$ & $21 \cdot 7$ & 5.9 & $21 \cdot 1$ & 6.5 & $20 \cdot 3$ & $6 \cdot 3$ & 0.14 & $0.02,0.26$ & 0.022 & 0.14 & $0.01,0.28$ & 0.041 \\
\hline Gross motor & $8 \cdot 6$ & $2 \cdot 6$ & $9 \cdot 0$ & 2.9 & $8 \cdot 3$ & 3.2 & 8.2 & $3 \cdot 1$ & 0.16 & $0.04,0.28$ & 0.011 & 0.19 & $0.05,0.32$ & 0.008 \\
\hline Fine motor & 5.9 & 1.9 & $6 \cdot 0$ & 1.9 & $5 \cdot 4$ & $2 \cdot 0$ & $5 \cdot 3$ & 1.9 & 0.07 & $-0.05,0.19$ & 0.269 & 0.06 & $-0.07,0.20$ & 0.366 \\
\hline Language & 3.4 & $2 \cdot 0$ & 3.5 & 1.9 & $3 \cdot 6$ & $2 \cdot 0$ & $3 \cdot 4$ & 1.9 & 0.08 & $-0.04,0.21$ & 0.171 & 0.09 & $-0.05,0.23$ & 0.191 \\
\hline Personal-social & 14.5 & 3.4 & $14 \cdot 7$ & 3.5 & 13.9 & $3 \cdot 7$ & $13 \cdot 6$ & 3.6 & 0.14 & $0.02,0.26$ & 0.026 & 0.13 & $-0.01,0.27$ & 0.067 \\
\hline Cognitive & 3.7 & 1.6 & 3.6 & $1 \cdot 6$ & 3.6 & $1 \cdot 8$ & $3 \cdot 3$ & $1 \cdot 8$ & 0.11 & $-0.01,0.23$ & 0.073 & $0 \cdot 11$ & $-0.02,0.25$ & 0.109 \\
\hline \multicolumn{15}{|c|}{ Children aged $12-18$ months } \\
\hline Motor development & $21 \cdot 1$ & 4.5 & $20 \cdot 9$ & 4.5 & $23 \cdot 2$ & $4 \cdot 4$ & $22 \cdot 7$ & 4.4 & 0.10 & $-0.02,0.22$ & 0.088 & 0.08 & $-0.06,0.21$ & 0.260 \\
\hline Mental development & $28 \cdot 3$ & $6 \cdot 0$ & $28 \cdot 1$ & $6 \cdot 1$ & $30 \cdot 7$ & $5 \cdot 1$ & $29 \cdot 8$ & $5 \cdot 3$ & $0 \cdot 16$ & $0.04,0.28$ & 0.009 & $0 \cdot 16$ & $0.02,0.29$ & 0.021 \\
\hline Gross motor & $13 \cdot 6$ & $3 \cdot 6$ & $13 \cdot 4$ & 3.7 & $15 \cdot 5$ & 3.5 & $15 \cdot 0$ & 3.5 & 0.13 & $0.02,0.25$ & 0.026 & 0.12 & $-0.02,0.25$ & 0.086 \\
\hline Fine motor & $7 \cdot 5$ & 1.5 & $7 \cdot 5$ & 1.5 & $7 \cdot 7$ & 1.5 & $7 \cdot 7$ & 1.4 & -0.01 & $-0.13,0.11$ & 0.883 & -0.05 & $-0.18,0.09$ & 0.486 \\
\hline Language & $5 \cdot 8$ & $2 \cdot 4$ & $5 \cdot 8$ & $2 \cdot 5$ & 6.9 & $2 \cdot 1$ & 6.5 & $2 \cdot 2$ & 0.21 & $0.09,0.33$ & 0.001 & 0.22 & $0.08,0.35$ & 0.002 \\
\hline Personal-social & $17 \cdot 8$ & $3 \cdot 3$ & $17 \cdot 7$ & $3 \cdot 3$ & $18 \cdot 8$ & $2 \cdot 8$ & $18 \cdot 4$ & $2 \cdot 9$ & 0.13 & $0.01,0.25$ & 0.031 & 0.13 & $0.00,0.26$ & 0.057 \\
\hline Cognitive & $4 \cdot 7$ & 1.4 & 4.5 & 1.5 & $5 \cdot 0$ & $1 \cdot 3$ & $4 \cdot 8$ & 1.3 & 0.00 & $-0.12,0.12$ & 0.970 & -0.02 & $-0.15,0.11$ & 0.778 \\
\hline
\end{tabular}

* All models account for clustering by health sub-centre and nested Anganwadi Centre. Model 1 is adjusting for age of the child. Model 2 is adjusting for the age of the child, baseline $\mathrm{Hb}$, baseline home stimulation score, wealth index, maternal education, caste and young mother. Effect sizes are calculated with adjusted means. Motor development scale ranges from 0 to 32 , mental development from 0 to 50 , gross motor from 0 to 22 , fine motor from 0 to 10 , language from 0 to 15 , personal-social from 0 to 28 and cognitive from 0 to 7. Children aged 6-11 months, $n 2208$ at baseline and $n 2004$ at endline; children aged 12-18 months, $n 2152$ at baseline and $n 2288$ at endline.

scores was significantly larger for children aged 12-18 months. Significant effect modification was seen by level of baseline household stimulation, but not by baseline $\mathrm{Hb}$. The effect of the intervention on motor and mental development, and language, and personal-social subscales, in children from households with high levels of stimulation was significantly more than that of children with low levels of household stimulation (online Supplementary Table S2). A significant dose-response was observed using numbers of MNP sachets consumed by the child over the previous month. At endline, among children from the intervention communities, scores for motor and mental development and each subscale (gross and fine motor, language, personal-social and cognitive development) were significantly higher in children who had received ten or more MNP sachets over the previous month compared with children who had received fewer sachets (online Supplementary Table S2).

\section{Impact of multiple micronutrient powders intervention on executive function and memory}

In children aged 12-18 months, there was no significant impact of the intervention on executive function outcomes. In the A-not-B task, there were no differences in the odds of tolerating a 3-, 6-, 9- and 12-s delay compared with no delay for the MNP intervention group compared with the control group (Table 4). We grouped all children who tolerated any delay because a small proportion (22\%) of children had a maximum tolerated delay between 0 and $12 \mathrm{~s}$ (i.e. a maximum tolerated delay of 3,6 or $9 \mathrm{~s}$ ). The majority of children who were able to tolerate any delay were able to tolerate a 12-s delay. There were no significant effects of the intervention on the odds of finding the toy under cloth A or the odds of perseverative error (not finding the toy under cloth B) (Table 4). Similarly, there was no effect of the intervention on memory scores using the Elicited Imitation task, whereby mean number of actions and pairs of actions complete in the correct order were not significantly different for the MNP intervention group compared with the control group (Table 4). There was no significant effect modification of the intervention from level of baseline household stimulation, baseline $\mathrm{Hb}$ nor was there a dose-response.

\section{Discussion}

This study was an effectiveness trial of home fortification with MNP, distributed through the existing health infrastructure in rural Bihar. Our findings indicate that the intervention had an impact on gross motor, language and personal-social development of children aged 6-18 months as measured by the DMC-II. The impact on motor development was significant in younger children aged 6-11 months, and the impact on 
Table 4. Executive function outcomes and mean scores on Elicited Imitation memory tasks for multiple micronutrient powders (MNP) intervention group and control group among children aged $12-18$ months $(n 1078)^{*}$

(Percentages and numbers; odds ratios and $95 \%$ confidence intervals; mean values and standard deviations)

\begin{tabular}{|c|c|c|c|c|c|c|c|c|c|c|}
\hline & \multicolumn{2}{|c|}{ Intervention } & \multicolumn{2}{|c|}{ Control } & \multicolumn{2}{|c|}{ Model 1} & \multirow[b]{2}{*}{$P$} & \multicolumn{2}{|c|}{ Model 2} & \multirow[b]{2}{*}{$P$} \\
\hline & $\%$ & $n$ & $\%$ & $n$ & OR & $95 \% \mathrm{Cl}$ & & OR & $95 \% \mathrm{Cl}$ & \\
\hline \multicolumn{11}{|l|}{ Executive function } \\
\hline \multicolumn{11}{|l|}{ Tolerated delay } \\
\hline None & $42 \cdot 8$ & 248 & $37 \cdot 3$ & 215 & Ref. & & & Ref. & & \\
\hline Any & $57 \cdot 2$ & 332 & $62 \cdot 7$ & 362 & 0.82 & $0.62,1 \cdot 1$ & 0.27 & 0.79 & $0.59,1.05$ & 0.10 \\
\hline Not found under cloth $A$ & $26 \cdot 1$ & 153 & $22 \cdot 9$ & 134 & Ref. & & & Ref. & & \\
\hline Found under cloth $\mathrm{A}$ & 73.9 & 434 & $77 \cdot 1$ & 451 & 0.85 & $0.57,1.25$ & 0.33 & 0.80 & $0.55,1.15$ & 0.22 \\
\hline Perseverative error & $32 \cdot 2$ & 189 & $28 \cdot 2$ & 165 & Ref. & & & Ref. & & \\
\hline \multirow[t]{2}{*}{ Found under cloth B } & $67 \cdot 8$ & 398 & $71 \cdot 8$ & 420 & 0.83 & $0.60,1 \cdot 16$ & 0.23 & 0.82 & $0.59,1.14$ & 0.23 \\
\hline & Mean & SD & Mean & SD & & & $P$ & & & $P$ \\
\hline \multicolumn{11}{|l|}{ Memory } \\
\hline Number of actions complete in all paradigms & 4.70 & $2 \cdot 20$ & 5.00 & 2.00 & & - & 0.43 & & - & 0.13 \\
\hline $\begin{array}{l}\text { Number of pairs of actions complete in the } \\
\text { correct order in all paradigms }\end{array}$ & $1 \cdot 70$ & $1 \cdot 30$ & 1.90 & $1 \cdot 20$ & & - & $0 \cdot 76$ & & - & 0.38 \\
\hline
\end{tabular}

Ref., referent value

* All models account for clustering by health sub-centre and nested Anganwadi Centre. Model 1 is adjusting for age of the child. Model 2 is adjusting for baseline mental development scores using Developmental Milestones Checklist II, baseline Hb, baseline home stimulation score, age of the child, examiner, wealth index, maternal education, caste and young mother. Any tolerated delay includes 3-, 6-, 9- and 12-s delay.

language development was significant in older children aged 12-18 months. Effects were modified by the baseline household stimulation, whereby the intervention had a larger impact in children with higher compared with lower stimulation at the start of the intervention. We observed no significant effect of the intervention on executive function or memory of children aged 12-18 months.

The motor and language development effect sizes we observed in our study are smaller than those from a previous effectiveness trial in children aged 6-24 months in Pakistan in which MNP were delivered by Lady Health Workers ${ }^{(7)}$. However, in the Pakistan study, mothers of children under 2 years were given MNP and nutrition education over a period of 18 months, which is longer than the current study. Another effectiveness trial in Bangladesh utilised staff from a community health and development programme and provided iron and folic acid supplements during monthly home visits to mothers during pregnancy until 3 months postpartum and a 15-nutrient MNP to the child from 6 to 24 months of age ${ }^{(9)}$. The trial found a significant impact on motor and language development, but no impact on personal-social development ${ }^{(9)}$.

In younger children aged 6-11 months, significant improvements were observed in the gross motor subscale from baseline to endline in the intervention group compared with the control group, whereas in children aged 12-18 months significant improvements were observed in the language development subscale. These findings suggest that infants' gross motor abilities were sensitive to the MNP supplementation from an early age, which may be because motor skills change more rapidly in the 1 st year rather than the 2 nd year of life ${ }^{(49-51)}$. Even though younger children would have received MNP for a shorter time period than older children, there is potential to benefit gross motor skills. Gross motor development itself has value for a young child in terms of increasing mobility; enhanced mobility can increase mental development especially if it raises the amount of environmental stimulation accessed by the child. The benefit to language development seen only in children after 12 months may be owing to MNP contributing to the 'language explosion' seen in the 2 nd and 3 rd year of life ${ }^{(52)}$ or to mothers' greater awareness of their child's language development owing to enhancement of children's overt speech at this age. Previous research has shown a similar impact of nutrition on expressive language in children above 1 year of age. A recent cluster-randomised trial in Bangladesh, which provided MNP to children between 7 and 12 months of age and followed them up at 16-22 months of age, found improvements in expressive, but not receptive, language development ${ }^{(10)}$. Standard deviations of scores are similar across both age groups in our sample, showing that children are not reaching a ceiling or floor score at the tail ends of the age range. The score was able to capture variability from 6 to 18 months of age. It is worth noting that many children in this population begin complementary feeding later than recommended ${ }^{(31)}$; only children who had begun complementary feeding would have been exposed to the MNP, which were designed to be mixed into the child's food.

Similarly to other recent nutrition interventions ${ }^{(9,53-55)}$, we did not find significant effects of the intervention on executive function or memory. The measures of executive function and memory could be insensitive to an MNP intervention in this age group (12-18 months of age), but effects may become apparent later throughout childhood. In infancy, executive functions are undifferentiated, or unrefined $^{(56)}$. Over the course of development, as a function of experience-dependent neural specialisation, executive function differentiates into distinct constructs, namely working memory, cognitive flexibility and inhibitory control $^{(56,57)}$. In addition, executive function differentiates from other cognitive functions, such as episodic memory ${ }^{(58)}$. Therefore, as cognitive functions differentiate, the effects of a nutrition intervention may become apparent on unique constructs. 
Executive function and memory are important predictors of school readiness and academic achievement ${ }^{(58-60)}$, even more so than intelligence quotient (IQ). As such, greater understanding of their response to nutrition interventions in early life should be prioritised for further research.

Our findings indicate that the intervention had a stronger impact on motor and mental development of children with a higher level of stimulation at baseline, suggesting that a minimum level of stimulation and resources at home are required before MNP interventions can provide benefits to development. These findings are consistent with the synergistic effect of stimulation and nutrition in early childhood. For instance, an effectiveness trial of iodised salt in Ethiopia found benefits of the intervention on mental development of children if their mothers had attended school ${ }^{(61)}$. Another study in Mexico resulted in larger impact of a group-based parenting programme on language development in children of mothers with any formal education compared with no education ${ }^{(62)}$. This threshold hypothesis is also supported by the literature showing larger gains in language and literacy outcomes from increases in quality of instruction for children from higher-quality classrooms compared with those from lower-quality classrooms ${ }^{(63)}$. However, these findings should be taken as preliminary given that the study design did not allow for follow-up of the same children and baseline values for stimulation were imputed.

Strengths of the study included its large sample size and cluster-randomised design, which allowed comparison across intervention and control communities. Clustering resulted in little contamination across groups. The use and validation of the tools to assess infant and young child development in rural northern India is an important addition to the literature. The DMC-II can be administered by trained non-specialists, and is a simple and quick measure of global development. The A-not-B and Elicited Imitation tasks require specialised training, but performed well in this context. Limitations of the study include the two cross-sectional surveys from baseline to endline rather than a follow-up of the same children. A longitudinal sample would have revealed differences in development outcomes on the same children and reduced confounding by having every child serve as their own control. However, the benefits of the design used, over following up the same children at two time points, are that every eligible child in the community received the intervention and no children were regarded as a special sample and given attention that would not model an effectiveness study. The timing of funding for the additional executive function and memory outcomes prevented us from measuring these cognitive functions at baseline. The lack of baseline measures precluded a difference-in-difference analysis. Some differences existed between intervention groups at baseline; however, these were accounted for in the statistical analyses. Mothers were not blinded to the intervention, and responses to the parent report DMC-II could have been biased by their expectations of the MNP. However, data collectors were blinded to the intervention group and would not have provoked a biased response.

The study's significant impact on child development is important to inform the IFHI and other state-level nutrition and early child development initiatives. The impact we observed on motor and mental development from the intervention is equivalent to 10 and $16 \mathrm{~d}$ of development, respectively, when we compare the observed estimates of the effects with the change in development scores by child age in months. Despite the moderate coverage of the intervention, these achievements are important in the context of a state with extremely poor nutritional indicators and extreme poverty. Further, the threshold effect we see from stimulation indicates that programmes addressing both stimulation and nutrition could have important implications on early child development.

\section{Acknowledgements}

The authors thank Priya Kekre for her contribution to the coordination of the study and data collection. In addition, the authors thank the collaborators, CARE India, as well as the women and children who participated in this study. Finally, the authors thank the Laney Graduate School at Emory University for funding L. M. L. while she pursued her PhD.

Funding support was provided by a Bill and Melinda Gates Foundation grant through a subcontract with CARE India, and the Thrasher Research Fund. Study funders did not have a role in the study design, data collection or manuscript preparation.

The authors' responsibilities were as follows: L. M. L. designed the child development component of the study, supervised data collection, analysed the data and drafted the initial manuscript; R. M. coordinated the study in the field; M. F. Y., P. J. B., U. R., A. W. G., P. V., I. C., S. S. and R. M. contributed to the design of the study, supervised data collection and critically reviewed the manuscript. S. S. and R. M. secured funding from the Bill and Melinda Gates Foundation, and R. M., L. M. L. and M. F. Y. secured funding from the Thrasher Research Fund for the study. All authors read and approved the final manuscript as submitted.

The authors declare that there are no conflicts of interest.

\section{Supplementary material}

For supplementary material/s referred to in this article, please visit https://doi.org/10.1017/S000711451800140X

\section{References}

1. Black MM, Walker SP, Fernald LC, et al. (2017) Early childhood development coming of age: science through the life course. Lancet 389, 77-90.

2. Grantham-McGregor S, Cheung YB, Cueto S, et al. (2007) Developmental potential in the first 5 years for children in developing countries. Lancet 369, 60-70.

3. Black RE, Victora CG, Walker SP, et al. (2013) Maternal and child undernutrition and overweight in low-income and middle-income countries. Lancet 382, 427-451.

4. Prado EL \& Dewey KG (2014) Nutrition and brain development in early life. Nutr Rev 72, 267-284.

5. Aboud FE \& Yousafzai AK (2015) Global health and development in early childhood. Annu Rev Psychol 66, 433-457.

6. Larson LM \& Yousafzai AK (2017) A meta-analysis of nutrition interventions on mental development of children under-two in low- and middle-income countries. Matern Child Nutr 13, e12229. 
7. Yousafzai AK \& Aboud F (2014) Review of implementation processes for integrated nutrition and psychosocial stimulation interventions. Ann N Y Acad Sci 1308, 33-45.

8. Yousafzai AK, Rasheed MA, Rizvi A, et al. (2014) Effect of integrated responsive stimulation and nutrition interventions in the Lady Health Worker programme in Pakistan on child development, growth, and health outcomes: a clusterrandomised factorial effectiveness trial. Lancet 384, 1282-1293.

9. Matias SL, Mridha MK, Tofail F, et al. (2017) Home fortification during the first $1000 \mathrm{~d}$ improves child development in Bangladesh: a cluster-randomized effectiveness trial. $\mathrm{Am} \mathrm{J}$ Clin Nutr 105, 958-969.

10. Singla DR, Shafique S, Zlotkin SH, et al. (2014) A 25-element micronutrient powder benefits language but not cognition in Bangladeshi full term low birth weight children. $J$ Nutr 144, 1803-1810.

11. Georgieff MK (2007) Nutrition and the developing brain: nutrient priorities and measurement. Am J Clin Nutr $\mathbf{8 5}$, 614s-620s.

12. Colombo J (1993) Infant Cognition: Predicting Later Intellectual Functioning, vol. 5. Newbury Park: Sage Publications.

13. Kail R (1988) Developmental functions for speeds of cognitive processes. J Exp Child Psychol 45, 339-364.

14. Wainwright PE \& Colombo J (2006) Nutrition and the development of cognitive functions: interpretation of behavioral studies in animals and human infants. Am J Clin Nutr 84, 961-970.

15. Christian P, Murray-Kolb LE, Tielsch JM, et al. (2014) Associations between preterm birth, small-for-gestational age, and neonatal morbidity and cognitive function among school-age children in Nepal. BMC Pediatr 14, 58.

16. Diamond A, Prevor MB, Callender G, et al. (1997) Prefrontal cortex cognitive deficits in children treated early and continuously for PKU. Monogr Soc Res Child Dev 62, i-v, 1-208.

17. Burden MJ, Westerlund AJ, Armony-Sivan R, et al. (2007) An event-related potential study of attention and recognition memory in infants with iron-deficiency anemia. Pediatrics 120, e336-e345.

18. Colombo J, Zavaleta N, Kannass KN, et al. (2014) Zinc supplementation sustained normative neurodevelopment in a randomized, controlled trial of Peruvian infants aged 6-18 months. J Nutr 144, 1298-1305.

19. Nelson CA, Wewerka S, Thomas KM, et al. (2000) Neurocognitive sequelae of infants of diabetic mothers. Behav Neurosci 114, 950.

20. Lu C, Black MM \& Richter LM (2016) Risk of poor development in young children in low-income and middleincome countries: an estimation and analysis at the global, regional, and country level. Lancet Glob Health 4, e916-e922.

21. Fernandez-Rao S, Hurley KM, Nair KM, et al. (2014) Integrating nutrition and early child-development interventions among infants and preschoolers in rural India. Ann NY Acad Sci 1308, 218-231.

22. Hirve S, Martini E, Juvekar SK, et al. (2013) Delivering sprinkles plus through the integrated child development services (ICDS) to reduce anemia in pre-school children in India. Indian J Pediatr 80, 990-995.

23. International Institute of Population Sciences (2016) National Family Health Survey (NFHS-4), 2015-2016. Mumbai: International Institute of Population Sciences.

24. World Health Organization (2011) Guideline: Use of Multiple Micronutrient Powders for Home Fortification of Foods Consumed by Infants and Children 6-23 Months of Age. Geneva: WHO. http://whqlibdoc.who.int/publications/2011/ 9789241502047_eng.pdf
25. Young M, Kekre P, Verma P, et al. (2015) A formative research study to integrate home fortification of complementary foods into a family health program in Bihar: process and methodology. Eur J Nutr Food Safety 5, 534-535.

26. Murray DM (1998) Design and Analysis of Group-Randomized Trials, vol. 29. New York: Oxford University Press.

27. National Institute of Nutrition (2010) Nutrient Requirements and Recommended Dietary Allowances for Indians. A Report of the Expert Group of the Indian Council of Medical Research. Hyderabad: National Institute of Nutrition.

28. Prado EL, Abubakar AA, Abbeddou S, et al. (2014) Extending the developmental milestones checklist for use in a different context in sub-Saharan Africa. Acta Paediatr 103, 447-454.

29. Bayley N (2006) Bayley Scales of Infant Development Manual, 3rd ed. San Antonio, TX: The Psychological Corporation.

30. Abubakar A, Holding P, Van de Vijver F, et al. (2010) Developmental monitoring using caregiver reports in a resourcelimited setting: the case of Kilifi, Kenya. Acta Paediatr 99, 291-297.

31. Larson LM, Young MF, Ramakrishnan U, et al. (2017) A crosssectional survey in rural Bihar, India, indicates that nutritional status, diet, and stimulation are associated with motor and mental development in young children. J Nutr 147, 1578-1585.

32. Ahun M (2015) Maternal and child health and development in rural Ghana. Masters of Psychology Master's Thesis, McGill University.

33. Diamond A (1985) Development of the ability to use recall to guide action, as indicated by infants' performance on $\mathrm{AB}$. Child Dev 56, 868-883.

34. Bauer PJ (2010) Declarative memory in infancy: an introduction to typical and atypical development. Adv Child Dev Behav 38, 1-25.

35. Bauer PJ (2005) New developments in the study of infant memory. In Handbook of Research Methods in Developmental Science, pp. 467-488 [DM Teti, editor]. Oxford: Blackwell Publishing.

36. Reed JM \& Squire LR (1998) Retrograde amnesia for facts and events: findings from four new cases. J Neurosci 18, 3943-3954.

37. Hamadani JD, Tofail F, Hilaly A, et al. (2010) Use of family care indicators and their relationship with child development in Bangladesh. J Health Popul Nutr 28, 23.

38. World Health Organization (2008) Indicators for Assessing Infant and Young Child Feeding Practices: Part 1: Definitions. Geneva: WHO. http://apps.who.int/iris/bitstream/10665/43895/ 1/9789241596664_eng.pdf

39. Ballard T, Coates J, Swindale A, et al. (2011) Household Hunger Scale: Indicator Definition and Measurement Guide. Washington, DC: Food and Nutrition Technical Assistance II Project, FHI 360.

40. de Onis M, Onyango AW, Van den Broeck J, et al. (2004) Measurement and standardization protocols for anthropometry used in the construction of a new international growth reference. Food Nutr Bull 25, S27-S36.

41. World Health Organization (2011) Haemoglobin Concentrations for the Diagnosis of Anaemia and Assessment of Severity. Geneva: WHO. http://www.who.int/vmnis/indicators/haemoglobin.pdf

42. Young MF, Mehta R, Gosdin L, et al. (2017) Impact of home fortification of complementary foods program on child anemia and stunting in Bihar, India. FASEB J 31, 165-167.

43. Sun J, Mohay H \& O'Callaghan M (2009) A comparison of executive function in very preterm and term infants at 8 months corrected age. Early Hum Dev 85, 225-230.

44. Heathcock JC, Bhat AN, Lobo MA, et al. (2004) The performance of infants born preterm and full-term in the mobile paradigm: learning and memory. Phys Ther 84, 808-821. 
45. Portillo-Reyes V, Perez-Garcia M, Loya-Mendez Y, et al. (2014) Clinical significance of neuropsychological improvement after supplementation with omega-3 in 8-12 years old malnourished Mexican children: a randomized, double-blind, placebo and treatment clinical trial. Res Dev Disabil 35, 861-870.

46. Bhutta ZA, Das JK, Rizvi A, et al. (2013) Evidence-based interventions for improvement of maternal and child nutrition: what can be done and at what cost? Lancet 382, 452-477.

47. Sullivan KM, Mei Z, Grummer-Strawn L, et al. (2008) Haemoglobin adjustments to define anaemia. Trop Med Int Health 13, 1267-1271.

48. World Health Organization (2011) WHO Child Growth Standards SAS igrowup package. Geneva: WHO. http://www. who.int/childgrowth/software/readme_sas.pdf

49. Thelen E (1985) Developmental origins of motor coordination: leg movements in human infants. Dev Psychobiol 18, 1-22.

50. Wijnhoven TM, de Onis M, Onyango AW, et al. (2004) Assessment of gross motor development in the WHO Multicentre Growth Reference Study. Food Nutr Bull 25, S37-S45.

51. Rubio-Codina M, Araujo MC, Attanasio O, et al. (2016) Concurrent validity and feasibility of short tests currently used to measure early childhood development in large scale studies. PLOS ONE 11, e0160962.

52. McMurray B (2007) Defusing the childhood vocabulary explosion. Science 317, 631 .

53. Prado EL, Maleta K, Ashorn P, et al. (2016) Effects of maternal and child lipid-based nutrient supplements on infant development: a randomized trial in Malawi. Am J Clin Nutr 103, 784-793.

54. Warthon-Medina M, Qualter P, Zavaleta N, et al. (2015) The long term impact of micronutrient supplementation during infancy on cognition and executive function performance in pre-school children. Nutrients 7, 6606-6627.

55. Yousafzai AK, Obradovic J, Rasheed MA, et al. (2016) Effects of responsive stimulation and nutrition interventions on children's development and growth at age 4 years in a disadvantaged population in Pakistan: a longitudinal follow-up of a cluster-randomised factorial effectiveness trial. Lancet Glob Health 4, e548-e558.

56. Zelazo PD, Anderson JE, Richler J, et al. (2013) II. NIH Toolbox Cognition Battery (CB): measuring executive function and attention. Monogr Soc Res Child Dev 78, $16-33$.

57. Miyake A, Friedman NP, Emerson MJ, et al. (2000) The unity and diversity of executive functions and their contributions to complex 'Frontal Lobe' tasks: a latent variable analysis. Cogn Psychol 41, 49-100.

58. Bauer PJ, Dikmen SS, Heaton RK, et al. (2013) III. NIH Toolbox Cognition Battery (CB): measuring episodic memory. Monogr Soc Res Child Dev 78, 34-48.

59. Blair C \& Razza RP (2007) Relating effortful control, executive function, and false belief understanding to emerging math and literacy ability in kindergarten. Child Dev 78, 647-663.

60. Eigsti IM, Zayas V, Mischel W, et al. (2006) Predicting cognitive control from preschool to late adolescence and young adulthood. Psychol Sci 17, 478-484.

61. Aboud FE, Bougma K, Lemma T, et al. (2017) Evaluation of the effects of iodized salt on the mental development of preschool-aged children: a cluster randomized trial in northern Ethiopia. Matern Child Nutr 13, e12322.

62. Fernald LC, Kagawa RM, Knauer HA, et al. (2017) Promoting child development through group-based parent support within a cash transfer program: experimental effects on children's outcomes. Dev Psychol 53, 222-236.

63. Zaslow M, Anderson R, Redd Z, et al. (2016) I. Quality thresholds, features, and dosage in early care and education: introduction and literature review. Monogr Soc Res Child Dev 81, 7-26. 